2018-07-10

\title{
Personal Engagement, emotion and the educational workplace
}

\author{
Crawford, Megan
}

http://hdl.handle.net/10026.1/11414

10.1108/jpcc-12-2017-0032

Journal of Professional Capital and Community

Emerald

All content in PEARL is protected by copyright law. Author manuscripts are made available in accordance with publisher policies. Please cite only the published version using the details provided on the item record or document. In the absence of an open licence (e.g. Creative Commons), permissions for further reuse of content should be sought from the publisher or author. 


\section{Personal engagement, emotion and the educational workplace}

\begin{tabular}{|r|l|}
\hline Journal: & Journal of Professional Capital \& Community \\
\hline Manuscript ID & JPCC-12-2017-0032.R2 \\
\hline Manuscript Type: & Research Paper \\
\hline Keywords: & emotion, Teamwork, teacher, personal, engagement \\
\hline
\end{tabular}

\section{SCHOLARONE}

Manuscripts 


\section{Personal engagement, emotion and the educational workplace}

Abstract: This article identifies the educational workplace as a site of complex social and relational interactions, and asks how recent research on emotion in education, and the concept of personal engagement, can enhance practice. Drawing on the research in these two areas, it seeks to bring together these concepts so that teachers can utilise these linkages to develop their professional practice. The article also asks how and in what ways such conceptual modelling might be related to professional capital. It then looks at how knowledge of personal engagement and emotion can be applied to professional settings, and as a starting point for further conceptualisations of the key issues involved. It ends with a return to the importance of understanding teaching as an emotional practice, and the role of engagement in building up teachers' professional capital.

\section{Introduction}

Hargreaves (2000) reminds educators that teaching is an emotional practice, something that may get lost in the framing of school work around performance indicators and/or test results, because emotional understanding is fundamental to both achieving and maintaining standards. He also notes (2000: 824) that this dimension of practice is not just about individual emotions, but also about how they are worked out in human relationships within organisations, in daily interactions, and relationships. In their seminal article, Ashford and Humphrey (1995: 119) suggest that 'the experience of work is saturated with emotion and that emotionality and rationality are interpenetrated'. They equate personal engagement with emotion, noting, 'the crucial role of personal engagement (emotion)' (p 119), yet this sense of emotion and engagement seems to have been dispersed over time, as the literature and the definitions of both emotion and engagement have proliferated. We know that schools are places of complex social and relational interactions, and there are many ways of looking at how such interactions work in practice. This article takes its lead from the work that has been carried out on affect in organisations in recent years, and aims to do two things; first, develop the conceptual linkage between teacher's personal engagement and affect; and second, utilize such conceptual modelling to see how professionals can enhance their own, or their team's, professional capital (Hargreaves and Fullan 2012). 
Engagement was first popularized by Kahn (1990), and the concept of personal engagement draws on his work. This article draws on that seminal study, and the work of Rich et.al (2010: 617) who extended Kahn's work, to suggest that engagement is a key mechanism that can explain some of the particular relationships between individual characteristics, organisational factors and job performance. I will argue that these relationships link to the concept of professional capital which Hargreaves and Fullan (2012) describe as comprised of "human capital (the talent of individuals); social capital (the collaborative power of the group); and decisional capital (the wisdom and expertise to make sound judgments about learners that are cultivated over many years)." (p.37). Personal engagement/emotion, may enable teachers to invest long-term in developing their professional capital. Hargreaves (1998a, p. 835) puts this clearly when he notes: "Good teachers are not just well-oiled machines. They are emotional, passionate beings. Teaching cannot be reduced to technical competence or clinical standards. It involves significant emotional understanding."

The aim of this article overall is to bring the concepts of personal engagement and emotion in an educational context to the fore. I will suggest that this bringing together of emotion and engagement not only takes the focus back to the original work in this area by Kahn (1990), but also links clearly with the social and human capital of teachers in the workplace. In particular, the article seeks to conceptualise personal engagement in a way that emphasizes the interactivity integral to the idea. I will argue that focusing on personal engagement can help understand not only some of the complex emotions of the educational setting, but also refresh the relationship between emotions and engagement in schools, and offer the beginnings of a conceptual model that could have relevance for both teachers and leaders alike. The article does not attempt to integrate all the literature in these areas, as this would not be possible in a single paper. Rather it seeks to draw out factors that teachers and researchers can use to make links between different but related concepts by providing a research context for these arguments. To do this, I will first suggest a definition of engagement, and frame its relationship to emotion, and then proceed to offer a brief overview of the literature, and finally suggest next steps. 


\section{Conceptualising engagement}

What is meant by engagement permeates any discussion which follows. The idea of engagement is a contentious one in the literature. Too often, the idea of engagement can be viewed as a shorthand or catch all for work-related attitudes. Definitions are extremely important in any discussions of engagement because the literature is often unclear about what engagement means not only conceptually but also in how that concept is put into practice in the workplace. There are many definitions in the literature, and researchers and writers in the field all take different aspects to make their own particular definition. A useful overview is given by Briner (2017). He argues "The one thing everyone knows about engagement is that nobody agrees what it is. For example, McLeod and Clarke (2009) stated: 'There is no one agreed definition of employee engagement - during the course of this review we have come across more than 50 definitions'. Not only are definitions numerous but, more importantly, they are very different (see Robertson-Smith and Marwick, 2009). (p4)". Briner provides some of the key foci that definitions have clustered around, ranging from employee behaviour to specific attitudes, feelings or commitment to the organisation.

In this article, the focus is on the personal aspect, so a return to the original definition given by Kahn (1990), (whose work started the focus on engagement in management literature) is a good place to begin. Kahn defines personal engagement as: the simultaneous employment and expression of a person's 'preferred self' in task behaviours that promote connections to work and to others '(1990,p. 700) (my italics). Following on from that initial definition, as noted at the start of the article, Rich et.al built on Kahn's work, to suggest that engagement is a key means of explaining the particular relationships between individual characteristics, organisational factors and job performance. For them (2010, p617), engagement "represents the simultaneous investment of cognitive, affective, and physical energies into role performance", and this is the overarching definition that frames this article. This definition keeps the focus on what it means to be personally engaged and underlines the complex relationship between task performance and the behaviour of the individual in a specific organisation. It also relates to professional capital in that 'promoting connections to work and to others' presents a clear connection to the argument that Hargreaves and Fullan make that social capital is more important than individual human capital, because it generates human capital faster (2012). 
Much of Kahn's work focuses on the motivational aspects of engagement. The motivation element was drawn upon by Ashforth and Humphrey (1995) when they explored engagement as a simultaneous expression of motivation and psychological involvement. Kahn expresses this aspect of engagement as follows: "Engagement is both very delicate and fragile, and quite resilient ... People have a desire to engage. They have an instinctive drive to express who they are, and who they wish to be, and given a chance at work, they will do so." (p.30) In his original ethnographic observational study, Kahn looks at personal engagement in a specific way - how the preferred and authentic self is expressed at work cognitively, emotionally and physically. It is this emotional aspect that has been shaped and expanded, I would argue, by more recent work on emotion. Such research shows how emotions are shaped by an individual's mood and their own personality traits (Scherer, 2009) such as agreeableness and anxiety (Lee and Ashton, 2010). Kahn notes that personal engagement or disengagement happens when 'people bring in or leave out their personal selves during work-role performances' (p. 702). This emotional investment of oneself into a work role is where aspects of human and social capital are combined in the workplace. If people are personally engaged at work, I would argue that professional capital is generated more effectively.

Kahn (1992) argues that engagement is embedded in the three psychological constructs of meaningfulness, safety and availability. Although there is not space to go into detail here, it is important to see how these constructs may aid understanding of personal engagement. May et al (2004:14) define meaningfulness as "the value of a work goal or purpose, judged in relation to an individual's own ideals or standards". This is where cognitive and emotional components combine. Psychological safety means that individuals feel able to express themselves in an organisational context without fear of any negative consequences, which causes difficulties perhaps for those working within high accountability and performativity cultures. Finally, availability is concerned with whether the individual has the personal resources, whether emotional, physical or psychological to engage with the tasks that the organisation sets them.

In terms of professional engagement and professional capital in school settings, the principal's role is a crucial one. Principals who are personally engaged are more likely to create a working environment where there is 'reciprocal collaboration, candid and vibrant 
dialogue, and a willingness to face uncertainty together' (Hargreaves 1997, p. 22). Through the principal, school climate is influenced. Hallinger and Heck suggest that the principal's role is 'best conceived as part of a web of environmental, personal, and in-school relationships that combine to influence organisational outcomes' (Hallinger \& Heck 1996, p. 6). Thus, principals' work involves building relationships, and helping others to build relationships. Understanding the role of emotion at work can help leaders engage with the social identity of teachers and focus on a building up professional capital in terms of the human and social side of work. By focusing on personal engagement and the intrapersonal and inter personal aspects of emotion, leaders can approach a complex area of study with greater awareness of the various factors involved. An understanding of the complex emotions in the workplace that affect personal engagement, and motivation will be part of the principals' role in relationship building. As well as motivation, McBain and Parkinson suggest that a fruitful area for study in this area of emotion and its relationship to personal engagement would be a further focus on friendship in the workplace and how friendship/affect acts as a key part of work life (2017). So we can see that the motivational aspects of personal engagement are key, are framed by the leaders in an educational setting, and are inevitably multifaceted. A way of bringing together what we have looked at so far can be seen in diagram 1 below with regard to teachers and principals:

\section{Personal engagement in educational settings: an overview}

\begin{tabular}{|c|c|}
\hline $\begin{array}{l}\text { Teachers' factors (individual) } \\
\text { - } \text { mood } \\
\text { - } \text { personality traits e.g. agreeableness } \\
\text { and anxiety } \\
\text { - motivation }\end{array}$ & $\begin{array}{l}\text { Principal factors (individual) } \\
\text { As for teachers' factors plus: } \\
\text { - skill in relationship building } \\
\text { - Accountability }\end{array}$ \\
\hline $\begin{array}{l}\text { Teacher/Principal (factors that apply to } \\
\text { both) } \\
\text { - meaningfulness, safety and } \\
\text { availability }\end{array}$ & $\begin{array}{l}\text { Societal factors } \\
\text { - } \text { history and demographic } \\
\text { environmental relationships } \\
\text { - Friendship }\end{array}$ \\
\hline
\end{tabular}




\section{Affect and personal engagement}

Affect and personal engagement then is a bringing together of many factors in an educational setting. There are many different perspectives on emotion in the research literature, but in general, the literature on 'emotion' relates particularly well to that of personal engagement because of the factors that were outlined above. For clarity, this article will draw upon the definition of emotion by Frijda (1986) that outlines the motivational and neurophysiological side of emotions, and the ways in which the individual can regulate emotions. Frijda argues that emotions arise because events are appraised by people as favorable or harmful to their own interests, and therefore are outcomes of the process of assessing the world in terms of an individual's own concerns, which, in turn, modify action readiness. Thus, emotion and cognition have an interactivity which more recent work emphasizes ( $\mathrm{Li}$ et al 2014), and can therefore be viewed as a form of engagement. Frijda's work looks at the place of emotion in motivation, and has been criticized by those who think Frijda's work gives insufficient attention to the social aspect of emotion.

This is where a focus on personal engagement in the educational context could be helpful for further research, and help with ambiguity. In a recent review, Ashkanasy and Dorris (2017: 68) note that 'ambiguity still surrounds the structure of the human affective experience', and go on to suggest that, crucially, there is still a limited framework of research on what they call the 'critical nexus' of emotion and cognition. Work tasks and work relationships form the relational context of self-engagement that is part of the intersection with emotion in school. Thus, personal relationships are a major part of engagement in schools, because schools are emotional workplaces (Crawford 2009, James 2010). Ashkanasy and Dorris (2017) argue that understanding the emotional side of work behaviour is vital in order for that organisation to avoid unpleasant or dark emotions such as bullying or unfair policies. They also point out that personal commitment to a workplace is intrinsically related to emotion in that it is a psychological state that binds an employee to an organisation" (p.69). If engagement represents the simultaneous investment of cognitive, affective, and physical energies into role performance, then it might be argued that the nature of schools as emotional workplaces creates a specific nexus where emotion is a key aspect. 
Humphrey, Ashforth and Diefendorff (2015), argue that emotions are signals of what is important to individuals in organisations (p.754). As well as signals of what is important, individual emotions will be invested in different ways, dependent on the role and the context. Thus, emotion can be seen at the very heart of personal engagement in the workplace, encompassing individual teachers and leaders.

In the last twenty years, research has focused around what Barsade et al. (2003) call the "Affective Revolution"-the causes and consequences of specific emotions and moods at work. One key work is Weiss and Cropanzano's (1996) Affective Events Theory (AET) for studying emotions, moods and job satisfaction at work. This emphasizes the nature of workplace emotions as being dynamic, which links to the dynamic nexus of the cognitive, affective and physical described above. AET argues that work behaviours (and performance) are linked to how individuals feel about their work at any specific moment in time. Various research derived from this approach (e.g. Basch and Fisher, 2000) suggests that emotions in a workplace tend to be linked to 'activating events', to which the members of that workplace can have specific, workplace specific responses. So, for example, responses in schools to difficult pupils or difficult members of staff will be made up of what Ashkanasy and Dorris (2017:72) call "specific sets of behavioural, cognitive and emotional reactions to emotional stimuli". A common theme throughout all this literature is the connective interactivity between the cognitive, emotion and physical, forming an individual's own personal engagement with the workplace.

Educational leaders' own personal engagement has assumed more importance in the educational leadership literature, with the re-focusing of attention onto emotion. Many writers (e.g. Hargreaves 2000;Boler 1999, Day, 2004, Harris 2004, Blackmore, 2004, Fineman, 2008, Crawford, 2009), look at how emotions are expressed and managed by individuals and by organisational processes. McBain and Parkinson (2017:201) bring this sharply into focus with their work on workplaces as social systems. They maintain that each individual's emotional and social needs are key to their behaviour at work. They also argue that writers need a greater understanding of the formal and informal contexts of work where personal engagement takes place. Dutton et al. (2010) suggest that being personally engaged at work enhances self-evaluations and self-development. In the Dutton et al. study, they found that happiness and pride are emotions that are most closely related to personal 
self-development at work, which in turn can be seen as investment in the cognitive and the emotional side of work.

Bringing many aspects of the above together is Ashkanasy's multi-level model of emotion (2003), which has been built upon by Ashkanasy and Dorris (2017), and draws on AET. This model suggests five levels of analysis when looking at emotions at work, which incorporates the personal, the inter personal, the intra personal, the team and the organisation. All these levels are very strongly linked together, and Ashkanasy and Dorris (p.81) suggest that, "emotions in workplace settings cannot really be understood as anything but a multilevel phenomenon of reciprocal and recursive relationships". This web of reciprocal and recursive relationships in schools is a key part of personal engagement, and social capital. These relationships also link to the third part of professional capitaldecisional capital-because professional support is vital when making difficult decisions in the challenging educational contexts that can arise in schools.

In addition to these different levels of analysis, Rothbard's work (2001) examines the multiplicity of work roles in any workplace, and asks which factors moderate the relationship between personal engagement in a role, and the type of emotional responses people may have within that role (2001:680). In this way, personal engagement can be seen in relationships with colleagues, with students, as well as with parents and other stakeholders. Thus, returning to Kahn's original idea of how personal engagement serves as a motivational force, he argues that personal engagement involves the individual unlocking of energy. Teachers' feelings about the external world of the school and their own internal world, work together to create their total experience of emotion at work and when positive, can unlock that energy. In the same way, Hargreaves argues that the power of professional capital helps groups of teachers to become more committed and collegial colleagues (2000). As Kahn and Heaphy $(2013 ; 92)$ state:

"The relational context of personal engagement is a crucial, if overlooked, dimension of engagement. Indeed work tasks cannot be clearly separated from work relationships... when workers are considered as persons, not just employees, relationships assume greater prominence..." (p. 92). Relatedly, Kahn (1998) also writes about personal engagement enabling people to give emotional and practical support.

Some ideas that practitioners could realistically utilize in order to enhance personal engagement, could be drawn out from various aspects of the above literature. For example, 
it was noted above that Kahn and others highlight the importance of psychological safety. If people are psychologically safe, they feel supported and may feel more able to take up challenges, or make decisions in a clear climate of acceptance. Whereas many aspects of current work in schools could be seen as activating instead areas of psychological threat, whether that be new and challenging ways of working, or dealing with specific accountability mechanisms (e.g OFSTED in England). An awareness of the multilevel phenomenon of emotion by school leaders can help teachers in the classroom engage more with the role of emotion in group settings. Leaders can attend to the individual and the collective, to make sure that teachers are personally engaged. This also means that leaders must be able to adjust individual and collective tasks to maximize personal engagement. If leaders are seen as being concerned with moving forward transformational processes within a school, then personal engagement is one such process that may be valuable for leaders to understand more clearly.

Leaders are often asked to change and challenge organisations in terms of norms and values, which can transform their whole organisational identity. Supporting personal engagement during times of organisational identity shift is a challenging task for leaders and their own personal engagement will be a key part of the process. A focus on the leader's feelings, and therefore a less 'rational' approach is also a feature of the work of Ackerman and Maslin-Ostrowski (2004). They argue for a "shift from the traditional cognitive realms to the affective with specific emphasis on immediate, subjective experience and perspectives capable of allowing for a deeper consideration of the inner emotional experiences of leadership." (p.312).

Fineman (2008) considers that feelings and emotions lubricate, rather than impair rationality, and suggests that they make difficult decisions possible, and ease dilemmas because what is important and worth thinking about in a situation is cued by emotion. As he argues, "We may collapse the rational/emotional distinction. Rationality is no longer the 'master process', neither is emotion. They both interpenetrate; they flow together from the same mould. From this perspective there is no such thing as pure cognition; thinking and deciding is always brushed with emotion, however slight...we may be dimly aware of these processes, or they may be unconscious."(Fineman, 2000, p.11). Allowing emotion in prompts leaders' understanding of how someone's inner world may have a profound impact 
on the rest of the school setting. I would argue that this is because leadership is an important and essential component in emotionally sustaining organisations.

\section{Summary and looking forward}

The literature on personal engagement is complex but, by specifically drawing on Kahn's original work, a model can be created that sees affective events combining at various levels (e.g. personal, interpersonal etc.) to make work outcomes more successful, just as professional capital can advance the work of teachers in schools. As Ashkanasy and Dorris (2017: 83) argue- there are many practical implications inherent in the study of emotion, and the role of personal engagement may be one of them. Leaders have the opportunity to enhance teachers' self-efficacy, and help enhance performance, by being personally engaged themselves, and understanding the benefits of managing specific emotional responses. Ashkanasy and Dorris cite the benefits of increasing affirmative resources in the workplace so that people will take "ownership of strengths and daily achievements at work', making work progress more effective. This brings the discussion back to where this article started and Kahn's (1998) argument that personal engagement enables people to give emotional and practical support to others. This dynamic interactivity of various complex concepts is a rich source of information for researchers and practitioners. However, it is also challenging, because of its complexity. For those wanting to move the discussion of engagement and emotion in the workplace forward, it is a challenge worth grappling with conceptually.

There are difficulties over definitions when discussing emotions. There are also arguments in the engagement literature about personal engagement and its relationship to emotion. Such ambiguity and inconsistency is unhelpful. A focus on personal engagement, whilst still having the potential for differential emphasis, could help raise awareness of the difficulties and opportunities that arise from studying workplace emotions.

In many educational settings, there are specific questions where a focus on personal engagement might yield benefits. In jurisdictions for example such as England, which face a teacher recruitment and retention crisis, further research on the conditions locally that improve personal engagement, perhaps through examination of how friendship groupings impact motivation, might be profitable. Focus on how personal engagement facilitates educational work for leaders and teachers could redraw the research emphasis in 
educational administration. Mapping across individuals in different workplaces in the same policy context is also an area that could be explored more deeply by examining individual personal engagement in the same context, and the factors that enhance or inhibit such engagement.

Multi-level analysis drawing on work such as Ashkanasy's presents another area for further inquiry. Bakker et al. (2008) when discussing occupational health more generally, draw on personal engagement to call for an emphasis on ' the positive, fulfilling, affectivemotivational state of work related well-being that is characterized by vigour, dedication and absorption' (p.187). The latter three attributes have clear connections to the simultaneous investment of cognitive, affective, and physical energies that make up personal engagement. A further extension of this would be to look at personal engagement in crosscultural settings.

\section{Conclusion}

In order to continue to work towards conceptual clarity, this article has considered a specific portion of the wide range of information that confronts readers when faced with the common, but ill-defined concept of workplace engagement, to see if the that literature offers anything that can usefully be applied to teachers, leadership in schools, and the emotional arena that is the school as a workplace. Noting the complexity of the task, this article has asked the reader to look at the ways that personal engagement and emotion are related to each other. The focus has been on what it might mean to be personally engaged, drawing specifically on the emotions literature and Kahn's work. Both teachers and those who lead educational organisations can gain new understandings of emotion and engagement, by focusing on what it means to be personally engaged in the workplace. The article has also suggested that there are some key connections to the focus of this journal, that of professional capital, because personal engagement in work will help build further professional capital in the school setting. This is because two of the key building blocks of professional capital are human capital and social capital. Personal engagement at work is built through human capital, yet at the same time human capital will build personal engagement. Personal engagement and emotion form an essential part of social capital as personal relationships are played out in the school as a workplace. 
Drawing on literature from health, business and educational backgrounds, I used Rich et al.'s definition of engagement at the beginning of this article, to suggest that engagement is a key mechanism which may explain some of the particular relationships between individual characteristics, organisational factors and job performance. Personal engagement is crucial to self-efficacy, and teacher resilience, because of the cognitive, affective, and physical energies that teachers bring into role performance. In addition, similar to mechanisms by which teachers are able to build social capital, Bakker and colleagues argue that people with high levels of personal engagement are able to perform better over time, as they continue to create their own personal resources, and by interacting with others, build up personal engagement through informal friendship groupings and through organisational structures. More research on the relationships between personal engagement, emotions and selfefficacy in education could take this idea forward, and expand our understandings of how both social and decisional capital may be influenced by personal engagement.

Briskin (1998) notes the complexity of such endeavours, as quoted in May et al. (2004, p11), and suggests that 'To explore the challenge to the human soul in organizations is to build a bridge between the personal, subjective, and even unconscious elements of individual experience and the world of organizations that demand rationality, efficiency, and personal sacrifice....we must be willing to shift our viewpoint back and forth between what organizations want of people and what contemplates human complexity: the contradictory nature of human needs desires and experiences.' At the beginning of this article I argued that recent studies on personal engagement can increase our understanding of how professionals work together. The plethora of research that has been carried out since Kahn's seminal article in 1990 has increased our knowledge of the role of emotion management (individually and organisationally) yet at the same time blurred the conceptual clarity around the idea of engagement. Returning to the original work that inspired this article, it can be seen that Kahn's aim was to 'map across individuals the general conditions of experience that influence degrees of personal engagement' (695), taking into account the multiple layers of influence that are within any work setting. As noted at the beginning of this article, his own work and that of others since has clarified more of those general conditions, and provoked more questions (Briner, 2017).

Kahn's original article looks at those particular moments of role performance that can help us understand larger and more complicated issues. He describes these as moments 
that are 'windows into the multiplicity of factors that are constantly relevant to person-role dynamics' ( $p$ 719). Such windows can be created through research, and by workplace initiatives. Although the multiplicity of factors involved, from policy context, to personal context may at times seem overwhelming, closer exploration of these factors could enable a move forward in the field's discussions concerning emotion, teaching, and the role of personal engagement in the workplace.

Even given this complexity, the arguments for continuing to unpack the issues are compelling. Building a bridge between the personal, subjective, and even unconscious elements of individual experience is hugely challenging. Linking those elements to the particular remit of leaders in schools is a difficult task, but one which challenges thinking around the relationships between emotion and leadership. Readers in school settings can expand their understanding of the leadership literature by asking how personal engagement can enhance professional practice for teachers and administrators alike. Drawing on what we already know from more recent research on emotion and personal engagement, there are important practical implications. For example, a clear focus for leaders could be on the structure of work and how they might be able to design or adjust these structures to enhance personal engagement. In particular, it may be pertinent to consider those workplace designs that take into account more fully issues such as the balance between autonomy and social support in the various interactions that teachers have with students, other staff and parents.

Effectively engaged teachers simultaneously invest their cognitive, affective and physical energies, which over time can become difficult if the school climate does not invest in energy renewal. An emphasis on personal engagement and emotion allows teachers to focus not only on their own personal engagement, but also enables them to work better in teams. Teachers' personal engagement and the amount of human and social capital they have built up will have individual differences due to their life as well as their work context. Personal engagement discussions as part of self-reflection, staff development or performance review would not be easy, but may be a key aspect of understanding more clearly the support mechanisms (personal and professional) that can be put in place for teachers. At the same time, workplace structure, and continuous professional development could aid teachers in strengthening their own personal engagement within the workplace. 
This article has mapped out a selection of important areas where further research, and re-conceptualization of personal engagement and emotions in the educational workplace could occur. Researchers could pay more attention to how personal engagement is connected to what we already know about emotion and schools. Developing the arguments about emotion and engagement should be an ongoing process for researchers in educational administration. In examining the literature, it is clear that although connections can be clearly drawn between personal engagement and emotion, there are benefits to viewing them as separate, as well as linked constructs. Although we know that the degree to which individuals in organisations regulate their emotions is variable, the impact of this variability on their personal engagement in classroom settings requires further research. Conceptually, this discussion may help us move towards a dynamic and multi-faceted model that brings together different ideas of personal engagement.

At the beginning of this article, I noted that teaching is an emotional practice, and the regulation and the engagement of emotion are part of this emotional practice. I have looked at how personal engagement could be seen as closely related to many areas of research on affect, and could have practical relevance for teachers in the settings in which they work. I have also situated this practical relevance in the context of professional capital and it's power as a mechanism for moving schools forward. Interwoven with decisional capital through the emotional dimensions of the decision-making process, and enhancing human and social capital through connections to developing professional knowledge and relationships, this article points to the ways in which personal engagement and emotion both support and sustain the essential components of professional capital within the educational workplace.

\section{References}

Ackerman, R. and Maslin-Ostrowski, P. (2004) The wounded leader and emotional learning in the schoolhouse, School Leadership and Management, Volume 24,Issue 3 pages 311-328 Ashford, B.E., Humphrey, R.H. (1995) Emotion in the workplace: A reappraisal, Human Relations, vol 48, 97-125

Ashforth,B.E. and Diefendorff, J.M. (2015) The bright side of emotional labor, Journal of Organisational Behaviour, 36 (6), 749-769 
Ashkanasy, Neal and Dorris, A. (2017) Emotions in the workplace, Annual Review of Organizational Psychology and Organizational Behaviour 4:67-90,

Bakker, A.B., Schaufeli, W.B., Leitner, M.P., Taris, T.W.(2008) Workplace engagement: An emerging concept in Occupational Health Psychology, Work and Stress, Vol 22, 3, 187-200

Barsade, S.G., Brief, A.P., Spataro, S.E (2003) The affective revolution in organisational behaviour: the emergence of a paradigm, in Organisational Behaviour: A Management Challenge, Greenberg, J.(ed)ps 3-52, Mahwah, NJ, Lawrence Elrbaum Associates

Basch, J. Fisher, C.D. (2000) Affective events-emotions matrix: a classification of work events and associated emotions, in Emotion in the Workplace, Research, Theory, and Practice, Ashkanasy, N., Hartel, D., Zerbe, W (eds.) pp.36-48, Conn. Quorum Books

Blackmore, J. (2004) 'Leading as Emotional Management Work in High Risk Times: The Counterintuitive Impulses of Performativity and Passion', School Leadership \& Management 24(4): 439-459.

Boler, M. (1999) Feeling Power. London: Routledge.

Briner, R (2017) What is employee engagement and does it matter?: An evidence-based approach, Engage for success thought piece http://engageforsuccess.org/the-future-ofengagement (accessed December 2017)

Burton, C., Buchan, L. Tarleton, R. (2015) Engagement and Wellbeing: an integrated model, www.designedforsuccess.co.uk

Corcoran, R., Tormey, R. (2013) Does Emotional Intelligence predict student performance?, Teaching and Teacher Education, 34-42

Day, C. (2004) 'The Passion of Successful Leadership', School Leadership \& Management 24(4), 425-437.

Dillon, P. Manz, C. (2016) A multilevel model of Managing Emotions in Transformational Organizational Identity Change, in Emotions and Organizational Governance, published online 08 June 2016

Dutton, J, Roberts, L.M., Bednar, J. (2010) Pathways for positive identity constructions at work: four types of positive identity and the building of social resources. Academy of Management Review, 35 (2), 265-293

Eckman, P. (1972) Universals and cultural differences in facial expressions of emotion, Nebraska Symposium on motivation, Vol 19, pp. 207-82, Univ of Nebraska Press

Fineman, S. (2008) The Emotional Organisation: Passion and Power. London: Blackwell. 
Frijda, N.H. (1986) The Emotions, New York : Cambridge University Press

Frijda, N.H. (2007) The laws of emotion, Routledge, Taylor and Francis

Hargreaves, A. (2000) Mixed emotions: teachers' perceptions of their interaction with students, Teaching and Teacher Education 16, 811-826

Hargreaves, A., Fullan, M (2012) Professional Capital: transforming teaching in every school, New York, N.Y. Teachers College Press.

Harris, B. (2004) 'Leading by Heart', School Leadership \& Management 24(4) 391-404. Univ of California Press

Humphrey, R.H. Ashforth,B.E. and Diefendorff, J.M. (2015) The bright side of emotional labor, Journal of Organisational Behaviour, 36 (6), 749-769.

Kahn, W.A. (1990) Psychological conditions of personal engagement and disengagement at work, Academy of Management Journal, 33, 692-724

Kahn, W.A. (1992) To be fully there: Psychological Presence at Work, Human Relations, Vol $45,0.4321-349$

Kahn, W.A. (1998)Relational Systems at Work, in Staw, B.B. and Cummings, L.L. (eds) Research in Organization behaviour, Vol 20, pp 39-76, Connecticut: JAI Press

Li, Y., Ashkanasy, N.M., and Ahlstrom, D. (2014) The rationality of emotions: a hybrid process of decision making under uncertainty. Asia Pacific Journal of Management 31: 293308

Linnenbrink-Garcia, L., Pekrun, R. (2011), Students' emotions and academic engagement: Introduction to the special issue, Contemporary Educational Psychology, 36, p. 1-3

May, D.R., Gilson, R.L., Harter, L.M (2004), The psychological conditions of meaningfulness, safety and availability and the engagement of the human spirit at work, Journal of Occupational and Organizational Psychology, 77, pp11-37

McBain, R., Parkinson, A (2017) Placing relationships in the Foreground: The role of workplace Friendships in engagement', Emotions and Identity, published online July, 119221

Meyer, J.P.and Herscovitch, L.(2001) Commitment in the Workplace Toward a General Model, Human Resource Management Review 11 pp. 299-326

Rich, B., Lepine, J., Crawford, E. (2010) Job engagement: Antecedents and effects on job performance, Academy of Management Journal, Vol. 53, no 3, p 617-635 
Rothbard, N.P. (2001) Enriching or Depleting? The Dynamics of engagement in work and family roles, Administrative Science Quarterly, Vo.I 46, 4, 655-684

Saks, A.M.(2006) Antecedents and consequences of employee engagement Journal of Management Psychology, 21, 600-619

Schaufeli, W.B., (2014) What is engagement? In Truss, C. et al (eds) Employee Engagement in theory and practice London

Weiss, H.M.and Cropanzano, R. (1996) Affective Events Theory: a theoretical discussion of the structure, causes and consequences of affective experiences at work, in Research in Organizational Behaviour: An Annual Series of Analytical essays and Critical Reviews, Vol 18, pp. 1-74 Greenwich Connecticut, JAI Press. 